\title{
Structural, Thermal, and Electrical Properties of PVA-Sodium Salicylate Solid Composite Polymer Electrolyte
}

\author{
Noorhanim Ahad, Elias Saion, and Elham Gharibshahi \\ Department of Physics, Faculty of Science, Universiti Putra Malaysia, 43400 UPM Serdang, Selangor, Malaysia \\ Correspondence should be addressed to Elias Saion, elias@science.upm.edu.my \\ Received 6 February 2012; Accepted 10 July 2012 \\ Academic Editor: Suprakas Sinha Ray
}

Copyright (C) 2012 Noorhanim Ahad et al. This is an open access article distributed under the Creative Commons Attribution License, which permits unrestricted use, distribution, and reproduction in any medium, provided the original work is properly cited.

\begin{abstract}
Structural, thermal, and electrical properties of solid composite polymer electrolytes based on poly (vinyl alcohol) complexed with sodium salicylate were studied. The polymer electrolytes at different weight percent ratios were prepared by solution casting technique. The changes in the structures of the electrolytes were characterized by XRD, which revealed the amorphous domains of the polymer which increased with increase of sodium salicylate concentration. The complexion of the polymer electrolytes were confirmed by FTIR studies. Thermal gravimetric analysis (TGA) was used to study the thermal stability of the polymer below $523 \mathrm{~K}$. The decomposition decreases with increasing sodium salicylate concentration. The conductivity and dielectric properties were measured using an impedance analyzer in frequency range of $20 \mathrm{~Hz}$ to $1 \mathrm{MHz}$ and narrow temperature range of 303 to $343 \mathrm{~K}$. The conductivity increased with increase of sodium salicylate concentration and temperature. The dielectric constant and dielectric loss increased with the increase in temperature and decreased with the increase in sodium salicylate concentration.
\end{abstract}

\section{Introduction}

Solid composite polymer electrolytes (SCPEs) have been extensively studied in the recent years due to their importance and their potential applications in electrochemical devices such as batteries, sensors, super capacitors, and fuel cells [1-4]. Most SCPEs consist of a host polymer to provide high dielectric strength and good mechanical stability and an inorganic salt that supplies ionic carriers to cause electrical conductivity $[4,5]$. They have unique properties which include film forming property, flexibility, light weight, fairly easy processability, elasticity, and high ionic conductivity. Examples of polymer electrolyte systems intensively studied were poly (ethylene oxide) (PEO) [6], poly (vinyl chloride) (PVC) [2], and poly (vinyl alcohol) (PVA) [2, 7].

One of such SCPE was a composite of PVA and Sodium Salicylate (SS), which is the subject of the present study. Among the polymers, PVA was especially attractive and was chosen as a polymer host since it is stable both thermally and environmentally, nontoxic, water soluble, and has good filmforming capacity [5]. Literature survey revealed that the ion transport studies of PVA doped with sodium salt polymer composite were scarce. In the present study, the structural, vibrational, thermal stability, and electrical studies of PVA polymer complexed with SS at different weight percent ratios were carried out by XRD, FTIR, TGA, and AC impedance measurements, respectively.

\section{Materials and Methods}

The glassy transparent host PVA polymer $(\mathrm{Mw}=$ $88,000 \mathrm{~g} / \mathrm{mol})$ at $88 \%$ hydrolyzed and sodium salicylate salt $\left(\mathrm{HOC}_{6} \mathrm{H}_{4} \mathrm{COONa}\right)$ were purchased (product of Acros, US) and used directly without further purification. The PVA was dissolved in deionized water at $90^{\circ} \mathrm{C}$ before adding SS salt which acts as an ionic dopant for the SCPEs. The SCPE films were prepared by solvent casting technique on the glass plates. Thick films of SCPEs between 80 to $220 \mu \mathrm{m}$ of PVA-SS composite were prepared at different weight percent PVA-SS ratios $(90: 0,80: 20,70: 30,60: 40$, and $50: 50)$.

The XRD analysis was carried out using Phillips X'pert $\mathrm{X}$-ray diffractometer with $\mathrm{Cu}-\mathrm{K}_{\alpha}$ radiation source at ambient temperature. The input voltage and current were $40 \mathrm{kV}$ and 


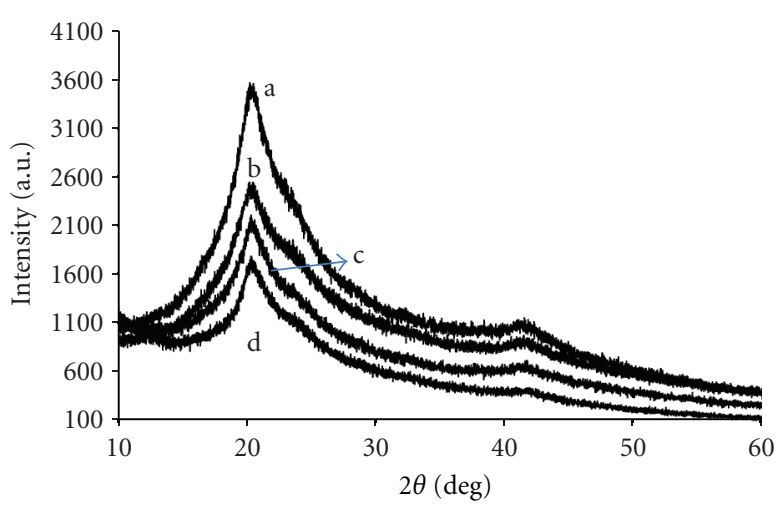

FIGURE 1: XRD pattern of PVA: $\mathrm{NaC}_{7} \mathrm{H}_{5} \mathrm{O}_{3}$ polymer electrolytes (a) pure PVA, (b) $90: 10$, (c) $80: 20$, and (d) $70: 30$.

$30 \mathrm{~mA}$, respectively. The XRD patterns were recorded for $2 \theta$ measurements from 5 to 60 degrees and the scanning times took approximately about 20 minutes. FTIR measurements were performed on a Perkin Elmer Spectrum 100 FTIRinstrument with a resolution of $2 \mathrm{~cm}^{-1}$. The measurements were taken over a wave number range of 280 to $4000 \mathrm{~cm}^{-1}$. Thermogravimetric analysis (TGA) was performed using Perkin Elmer TGA Instrument. Sample of about 2 to $12 \mathrm{mg}$ was placed in the specimen holder and initial mass was recorded and heating rate was set at $10^{\circ} \mathrm{C} / \mathrm{min}$ and the measurements were carried out in ambient atmosphere air from 35 to $500^{\circ} \mathrm{C}$.

A series of conductivity and dielectric measurements on the SCPE samples of different weight percent PVA : SS ratios were carried out over a frequency range of $100 \mathrm{~Hz}$ to $1 \mathrm{MHz}$ from the ambient temperature to $343 \mathrm{~K}$ using computercontrolled LCR meter (HP4284 A). Each film sample was sandwiched between two circular metal electrodes with the surface area of $4.90 \times 10^{-4} \mathrm{~m}^{2}$.

\section{Results and Discussion}

3.1. X-Ray Diffraction Analysis. Figure 1 presented XRD analysis for pure PVA and PVA-sodium salicylate composite with different compositions of sodium salicylate. It was found that the XRD pattern of pure PVA showed a broad peak around $20^{\circ}$ corresponding to semicrystalline nature of pure PVA $[6,8]$. In the present study, a decrease in intensity and an increase in broadness of the diffraction peak of pure PVA were observed with increase of sodium salicylate concentration. This result could be due to the disruption of the PVA crystallinity which revealed the amorphous nature of the PVA-sodium salicylate polymer composites. This amorphous nature results in greater ionic diffusivity with high conductivity for other systems $[8,9]$. A previous study reported that the intensity of XRD pattern decreases with increase of amorphous nature by addition of dopant [10]. This has established a correlation between the height of the peak and the degree of crystallinity. No new peaks corresponding to sodium salicylate were observed which indicate a complete dissolution of salt in the PVA polymer matrix.

3.2. FTIR Analysis. A FTIR spectroscopy was used to identify the compound and investigate the complexation and interactions in the polymer matrices. The FTIR spectra of pure PVA and PVA doped with 20, 40, and $50 \mathrm{wt} \%$ of SS are shown in Figure 2. After comparing the spectra of pure PVA with PVA-SS composites, several changes in the spectral features were observed and tabulated in Table 1. The peak centered at $3294 \mathrm{~cm}^{-1}$ assigned to the stretching vibration of hydroxyl groups $(\mathrm{O}-\mathrm{H})$ of pure PVA $[6,8]$ was shifted to 3309,3338 , and $3399 \mathrm{~cm}^{-1}$, respectively, in 20,40 , and $50 \mathrm{wt} \%$ SS in PVA-SS electrolyte system, which indicates the specific interaction in the polymer systems. In addition to this, the $\mathrm{C}-\mathrm{H}$ stretching of $\mathrm{CH}_{2}$ which showed absorption at $2934 \mathrm{~cm}^{-1}$ in pure PVA $[6,8,9]$ was shifted to 2930, 2935, and $3066 \mathrm{~cm}^{-1}$ in 20,40 , and $50 \mathrm{wt} \% \mathrm{SS}$, respectively. The peak at $1723 \mathrm{~cm}^{-1}$ corresponding to $\mathrm{C}=\mathrm{O}$ stretching of PVA $[4,8,9]$ was shifted to lower wave numbers in the 10,20 , and $30 \mathrm{wt} \% \mathrm{SS}$ but it disappeared in $40 \mathrm{wt} \% \mathrm{SS}$ system. The peak at $1427 \mathrm{~cm}^{-1}$ corresponds to $\mathrm{C}-\mathrm{H}$ bending of pure PVA $[6,8]$. This peak is shifted to 1451,1454 , and $1461 \mathrm{~cm}^{-1}$, respectively, in 20,40, and $50 \mathrm{wt} \% \mathrm{SS}$ systems. The vibration of $\mathrm{CH}_{2}$ group was found at $1372 \mathrm{~cm}^{-1}$ corresponding to C$\mathrm{H}$ wagging in pure PVA [6] and it was shifted to higher wave numbers in the complexed systems. Also, the peak at $1329 \mathrm{~cm}^{-1}$ that corresponds to $\mathrm{C}-\mathrm{H}$ wagging of pure PVA is absent in PVA-SS complexed systems. The C-C stretching vibration of PVA [8] appearing at $1249 \mathrm{~cm}^{-1}$ was shifted to 1252,1254 , and $1287 \mathrm{~cm}^{-1}$ in 20,40 , and $50 \mathrm{wt} \% \mathrm{SS}$ complexed systems, respectively. C-O stretching occurred at $1084 \mathrm{~cm}^{-1}$ in PVA [6] and it was shifted to $1085 \mathrm{~cm}^{-1}$ in $20 \mathrm{wt} \%$ SS electrolyte systems. For $40 \mathrm{wt} \%$ SS system, C-O stretching occurred at $1080 \mathrm{~cm}^{-1}$. This clearly showed that the interaction between the SS dopant salt and PVA in the polymer composite does not only arise from $\mathrm{O}-\mathrm{H}$ group but also from $\mathrm{C}-\mathrm{O}$ group of pure PVA. The vibration peak appearing at $836 \mathrm{~cm}^{-1}$ assigned to $\mathrm{C}-\mathrm{H}$ rocking mode of PVA $[6,9]$ was shifted to 848,851 , and $857 \mathrm{~cm}^{-1}$, respectively, in 20, 40, and $50 \mathrm{wt} \%$ SS complexed electrolyte systems. The shift of this wave number may be due to the interaction of proton in the salt with the carbonyl oxygen of PVA [2]. Also, new peaks at between $1425 \mathrm{~cm}^{-1}$ and $1628 \mathrm{~cm}^{-1}$ which were found in the polymer complex systems of $10,20,30$, and $40 \mathrm{wt} \%$ SS could be attributed to the carboxylate moiety $\left(\mathrm{COO}^{-}\right)$of sodium salicylate [11]. Hence, from the FTIR analysis, the complex formation of PVA polymer, and SS salt was confirmed.

3.3. TGA Analysis. The thermal stability of the solid composite polymer electrolytes is an important parameter to guarantee acceptable performance in electrochemical devices. Figure 3 shows TGA and differential gravimetric analysis (DTG) thermographs of PVA and PVA-SS composite polymer electrolytes with various SS compositions at a heating rate of $10^{\circ} \mathrm{C} / \mathrm{min}$ and in the temperature range of room temperature to $500^{\circ} \mathrm{C}$. A derivative weight loss 


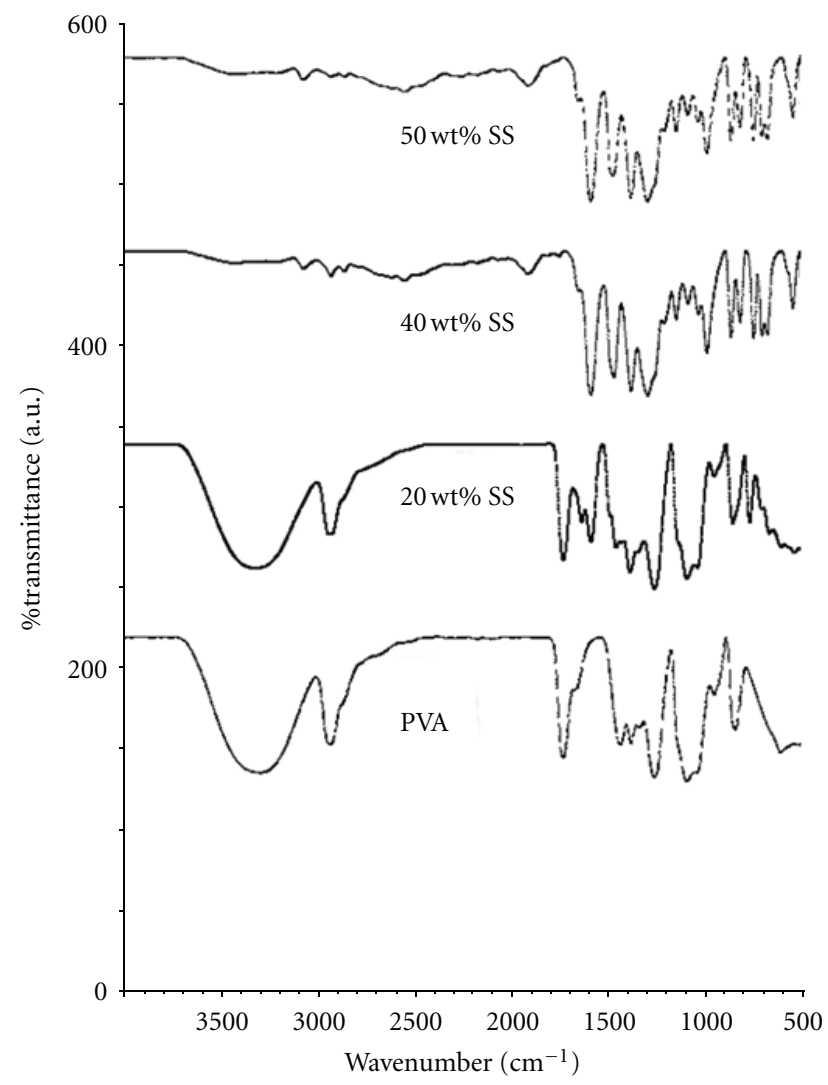

FIGURe 2: FTIR spectrum of pure PVA and PVA : $\mathrm{NaC}_{7} \mathrm{H}_{5} \mathrm{O}_{3}$ polymer electrolytes for 20,40 , and 50 wt $\%$ SS systems.

TABLE 1: FTIR band assignments of PVA-SS solid composite polymer electrolytes. The peaks assigned to PVA shifted to higher wavenumbers by increasing SS concentration.

\begin{tabular}{|c|c|c|c|c|c|c|}
\hline \multirow{3}{*}{ Pure PVA } & \multicolumn{4}{|c|}{ Wavenumber $\left(\mathrm{cm}^{-1}\right)$} & \multirow{3}{*}{$\begin{array}{c}\text { PVA : SS } \\
50: 50\end{array}$} & \multirow{3}{*}{ Band assignments } \\
\hline & PVA:SS & PVA:SS & PVA:SS & PVA:SS & & \\
\hline & $90: 10$ & $80: 20$ & $70: 30$ & $60: 40$ & & \\
\hline 3294 & 3298 & 3309 & 3338 & 3399 & 3402 & $\mathrm{O}-\mathrm{H}$ groups \\
\hline 2934 & 2932 & 2930 & 2935 & 3066 & 3066 & C-H stretching \\
\hline 1723 & 1722 & 1723 & 1721 & - & - & $\mathrm{C}=\mathrm{O}$ stretching \\
\hline 1427 & 1425 & 1451 & 1454 & 1461 & 1467 & $\mathrm{C}-\mathrm{H}$ bending \\
\hline 1372 & 1378 & 1379 & 1381 & 1373 & 1372 & $\mathrm{C}-\mathrm{H}$ wagging \\
\hline 1249 & 1253 & 1252 & 1254 & 1287 & 1286 & $\mathrm{C}-\mathrm{C}$ stretching \\
\hline 1084 & 1085 & 1085 & 1085 & 1080 & 1140 & $\mathrm{C}-\mathrm{O}$ stretching \\
\hline 944 & 944 & 946 & - & - & - & C-H stretching \\
\hline 836 & 843 & 848 & 851 & 857 & 856 & $\mathrm{C}-\mathrm{H}$ rocking \\
\hline - & $1425-1628$ & $1425-1628$ & $1425-1628$ & $1425-1628$ & $1425-1628$ & Carboxylate moiety $\left(\mathrm{COO}^{-}\right)$ \\
\hline
\end{tabular}

curve can be used to tell the point at which weight loss is most apparent. TGA and DTG curves of PVA and PVA-SS composite polymer electrolytes revealed three main weight loss regions. The initial weight loss for pure PVA occurred at a temperature region of 36 to $145^{\circ} \mathrm{C}$ with a sharp peak at $81^{\circ} \mathrm{C}$ in the DTG curve $\left(T_{\max , 1}=81^{\circ} \mathrm{C}\right)$, due to the evaporation of physically weak and chemically strong bound $\mathrm{H}_{2} \mathrm{O}$ from the polymer matrix [12-14]. The weight loss of this membrane was about $5.8 \mathrm{wt} \%$. It was also observed that the major weight losses have occurred in the range of 178 to $368^{\circ} \mathrm{C}\left(T_{\max , 2}=321^{\circ} \mathrm{C}\right)$. This is due to the degradation of side chain $(\mathrm{O}-\mathrm{H})$ of PVA and the weight loss corresponding to this stage was about $45 \mathrm{wt} \%$. Finally, the peak of the third stage temperature range between 370 and $473^{\circ} \mathrm{C}\left(T_{\max , 3}=413^{\circ} \mathrm{C}\right)$. This may correspond to the cleavage of $\mathrm{C}-\mathrm{C}$ backbone of PVA polymer or commonly called carbonation $[1,13,14]$, with a weight loss of $30 \mathrm{wt} \%$. 


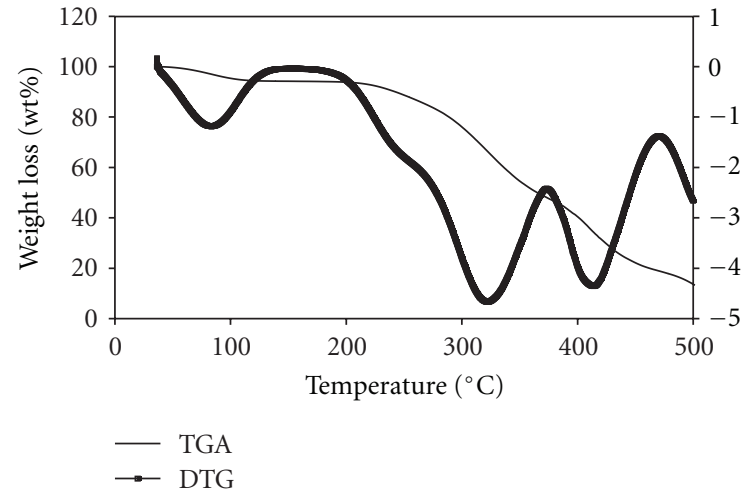

(a)

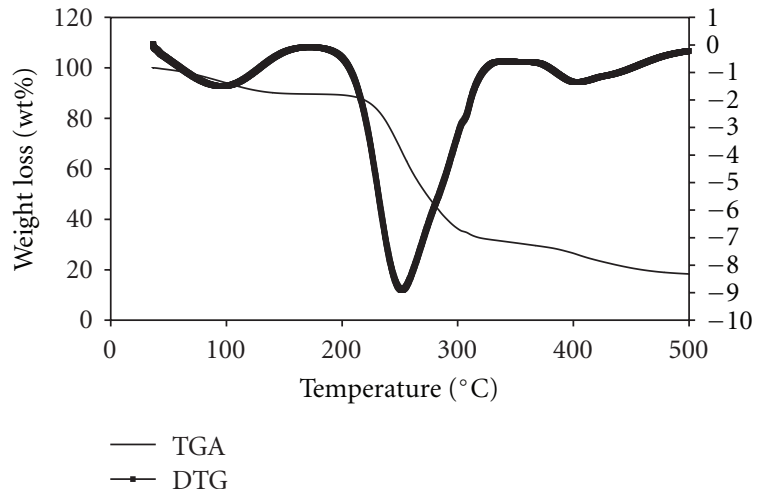

(c)

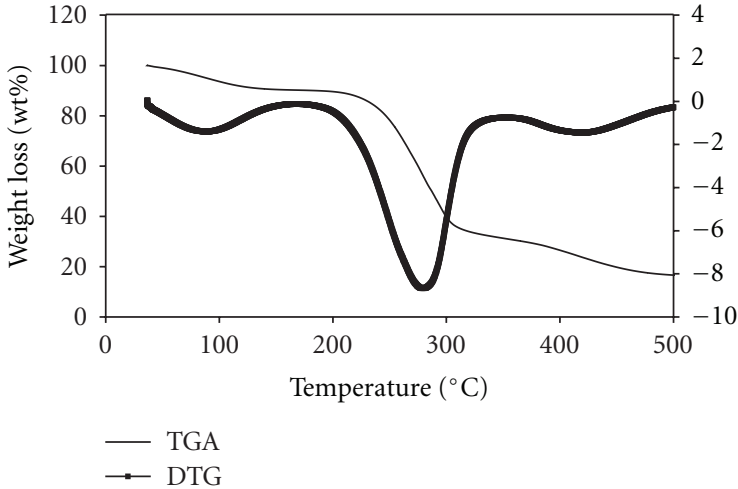

(b)

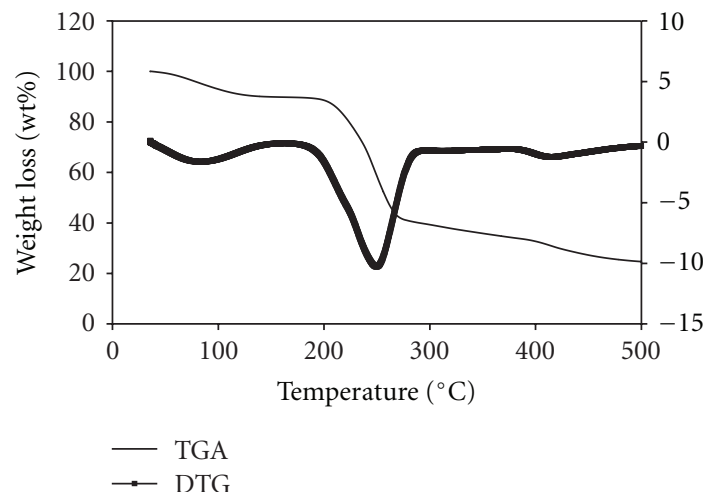

(d)

Figure 3: TGA and DTG plot of (a) pure PVA, (b) PVA- $10 \mathrm{wt} \%$ SS, (c) PVA-20 wt $\%$ SS, and (d) PVA-30 wt $\%$ SS.

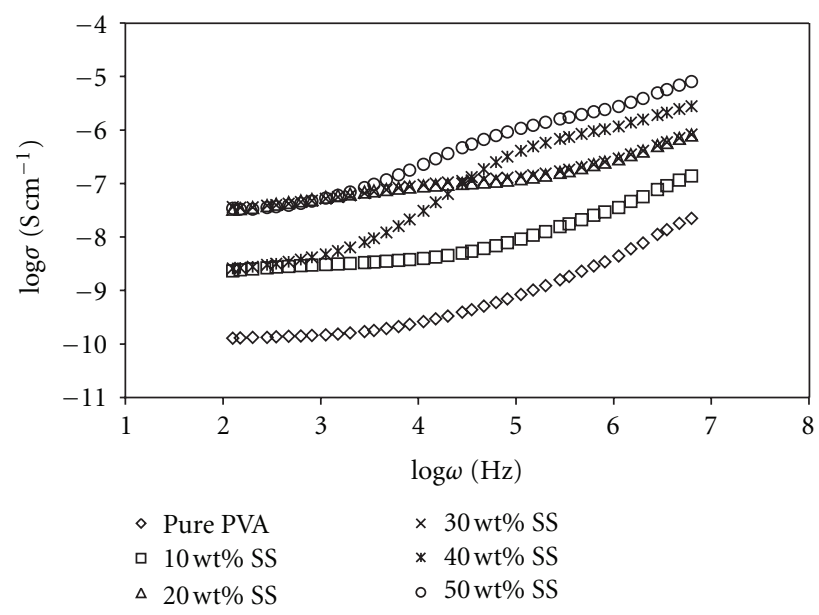

(a)

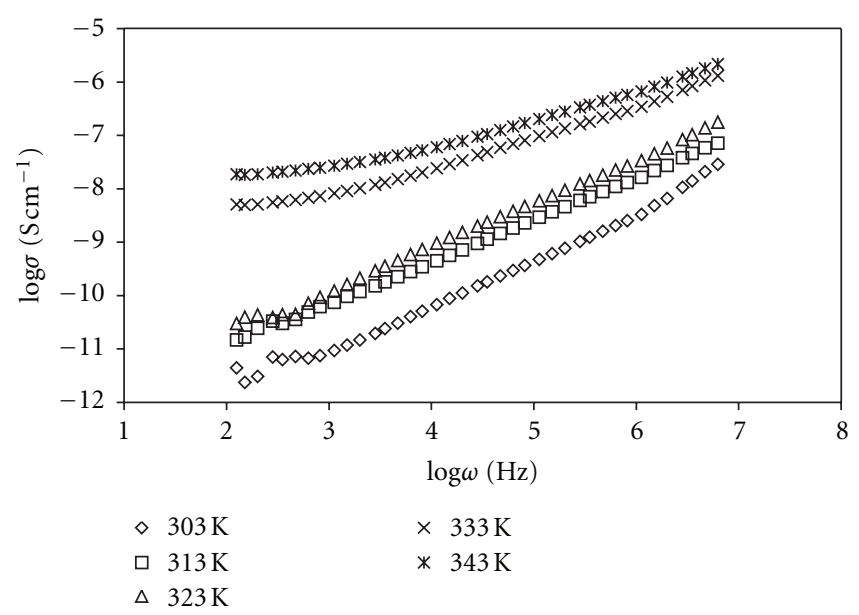

(b)

FIGURE 4: (a) Conductance spectra of PVA-sodium salicylate solid composite polymer electrolyte at $303 \mathrm{~K}$ for different SS concentrations. (b) Conductance spectra of PVA : $50 \mathrm{wt} \%$ SS solid composite polymer electrolyte at different temperatures.

The PVA-sodium salicylate solid composite polymer electrolytes of various compositions of sodium salicylate (10, 20 , and $30 \mathrm{wt} \%)$ also exhibited three major processes of weight losses for all the prepared samples shown in Figures $3(\mathrm{~b})-3(\mathrm{~d})$. The first region at a temperature range of 35 to $180^{\circ} \mathrm{C}$ observed was associated with the loss of $\mathrm{H}_{2} \mathrm{O}$ molecules. The weight loss was about 7.1 to $10.3 \mathrm{wt} \%$. The major weight losses were observed in the range of 177 to $338^{\circ} \mathrm{C}$ which may be due to the structural decomposition of the polymer systems and their complexes [12]. In this project, the decomposition of PVA and sodium salicylate may occur at this stage. The weight loss which corresponds 


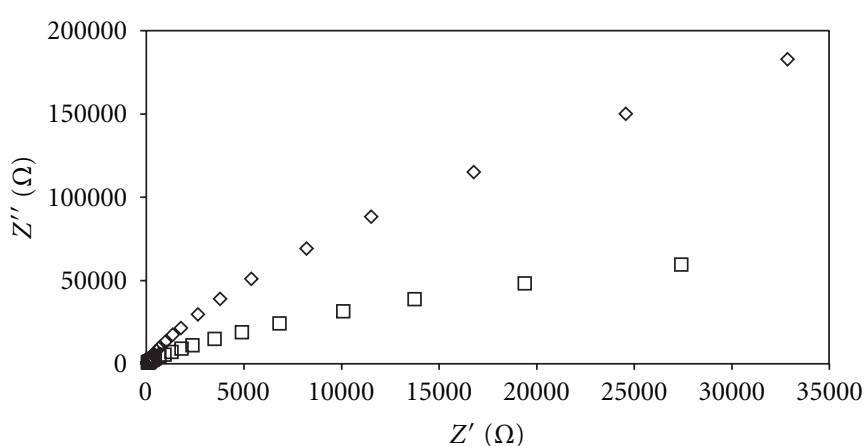

$\diamond$ Pure PVA

$10 \% \mathrm{SS}$

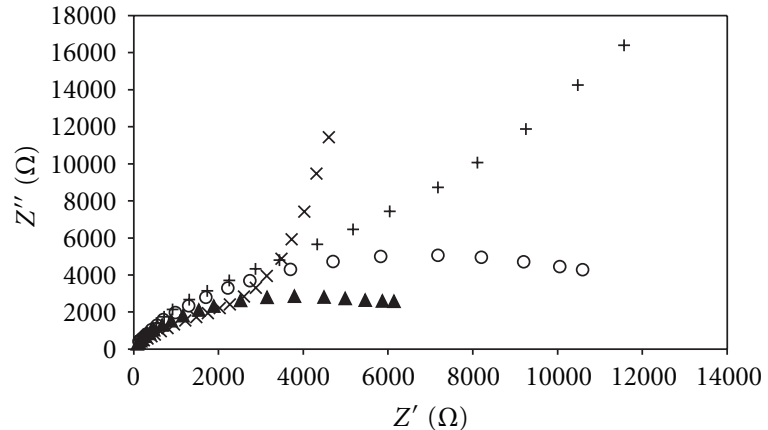

○ $20 \%$ SS

- $30 \%$ SS

$\times \quad 40 \%$ SS

$+50 \%$ SS (a1)

(a)

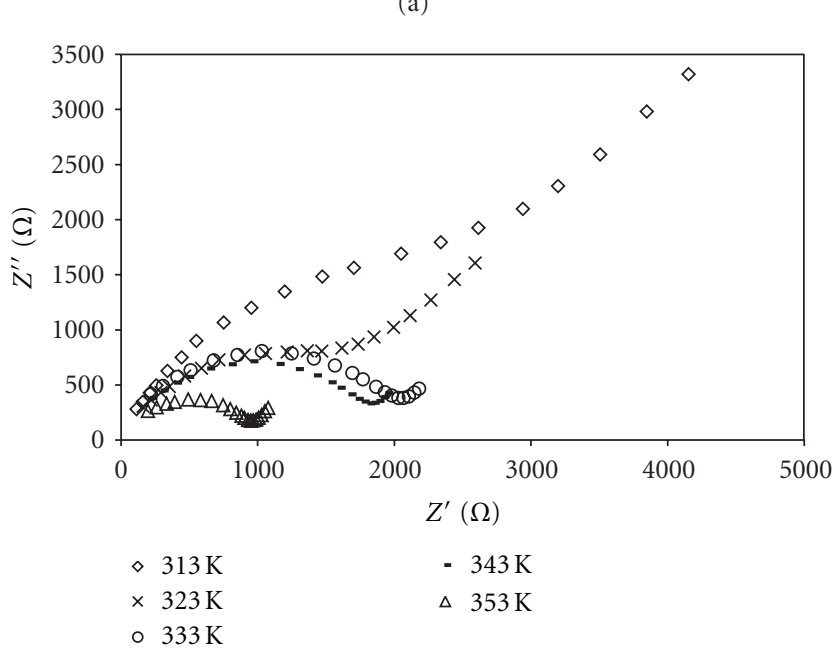

(b)

(a2)

FIgure 5: (a) Cole-cole plot of PVA-sodium salicylate solid composite polymer electrolyte at $303 \mathrm{~K}$ for different SS concentrations. (b) Cole-cole plot of PVA : $50 \mathrm{wt} \%$ SS solid composite polymer electrolyte at different temperatures.

to this stage was about $49-59 \mathrm{wt} \%$. The peak of the third stage at $350-500^{\circ} \mathrm{C}$ was due to the cleavage of the backbone of PVA polymer and the weight loss was about $5-15 \mathrm{wt} \%$. The decompositions of the samples as well as percentage weight loss were given in Table 1. It should be mentioned that the peaks of the first decomposition step were less intense and shifted towards higher temperature with increasing SS compositions, while the peak temperature of the second decomposition step decreases with increasing SS concentrations. Table 2 showed the value of weight loss was irregular for the first and second decomposition with increasing SS concentrations. However, the value of weight loss for the third decomposition step and the total weight loss decreases with increasing SS concentrations. Therefore, it could be concluded that the thermal stability of polymer electrolyte system improved due to the addition of SS salt.

3.4. Electrical Conductivity. Figures 4(a) and 4(b) show the conductance spectra for PVA-sodium salicylate composite electrolytes of various concentrations of sodium salicylate at $303 \mathrm{~K}$ and for the PVA-50 wt\% sodium salicylate sample at various temperatures up to $343 \mathrm{~K}$. The conductance spectrum consists of two distinct regions: the low frequency dispersion region, followed by the frequency independent plateau region. Low frequency dispersion was due to electrode-electrolyte or space charge polarization effects [1] and the frequency independent plateau region was connected with the DC conductivity of solid composite polymer electrolytes. In the low frequency region, more charge accumulation occurred at the electrode and electrolyte interface, leading to a decrease in the number of mobile ions and conductivity. The mobility of charge carriers was higher in the high-frequency region; hence the conductivity increases with frequency as reported earlier [9, 15]. In Figure 4(a), the results showed that the conductivity increases with an increase in sodium salicylate concentration throughout the measured frequency region due to the enhancement of the mobility of charge ions and the larger number of charge 
TABLE 2: TGA and DTG data for the solid composite polymer electrolytes.

\begin{tabular}{|c|c|c|c|c|c|}
\hline \multirow{2}{*}{ Sample } & \multicolumn{3}{|c|}{ Temperature ${ }^{\circ} \mathrm{C}$} & \multicolumn{2}{|c|}{ Weight loss (wt.\%) } \\
\hline & Start & End & $T_{\max }{ }^{\mathrm{a}}$ & Partial & Tota \\
\hline \multirow{3}{*}{ Pure PVA } & 36.3 & 143.7 & 80.9 & 5.8 & \multirow{3}{*}{86.4} \\
\hline & 178.9 & 368.7 & 321.3 & 44.9 & \\
\hline & 370.3 & 469.8 & 413.1 & 29.8 & \\
\hline \multirow{3}{*}{$\begin{array}{l}\text { PVA : SS } \\
90: 10\end{array}$} & 36.6 & 164.7 & 87.8 & 9.8 & \multirow{3}{*}{83.5} \\
\hline & 182.8 & 348.8 & 279.4 & 58.7 & \\
\hline & 350.3 & 519.2 & 415.18 & 15.0 & \\
\hline \multirow{3}{*}{$\begin{array}{l}\text { PVA : SS } \\
80: 20\end{array}$} & 36.5 & 161.4 & 95.9 & 10.3 & \multirow{3}{*}{81.7} \\
\hline & 187.3 & 338.1 & 251.3 & 58.1 & \\
\hline & 350.3 & 508.7 & 403.6 & 12.5 & \\
\hline \multirow{3}{*}{$\begin{array}{l}\text { PVA: SS } \\
70: 30\end{array}$} & 35.5 & 155.2 & 83.1 & 10.1 & \multirow{3}{*}{75.4} \\
\hline & 177.9 & 291.5 & 248.7 & 49.8 & \\
\hline & 384.9 & 526.5 & 414.3 & 9.8 & \\
\hline \multirow{3}{*}{$\begin{array}{l}\text { PVA: SS } \\
60: 40\end{array}$} & 37.6 & 170.1 & 90.9 & 9.7 & \multirow{3}{*}{76.7} \\
\hline & 179.5 & 295.9 & 246.2 & 51.7 & \\
\hline & 387.6 & 502.6 & 414.0 & 9.6 & \\
\hline \multirow{3}{*}{$\begin{array}{l}\text { PVA : SS } \\
50: 50\end{array}$} & 36.1 & 180.4 & 131.4 & 7.2 & \multirow{3}{*}{72.1} \\
\hline & 185.0 & 351.9 & 246.2 & 59.0 & \\
\hline & 380.9 & 497.3 & 420.7 & 5.4 & \\
\hline
\end{tabular}

${ }^{\mathrm{a}}$ Peak temperature of DTG.

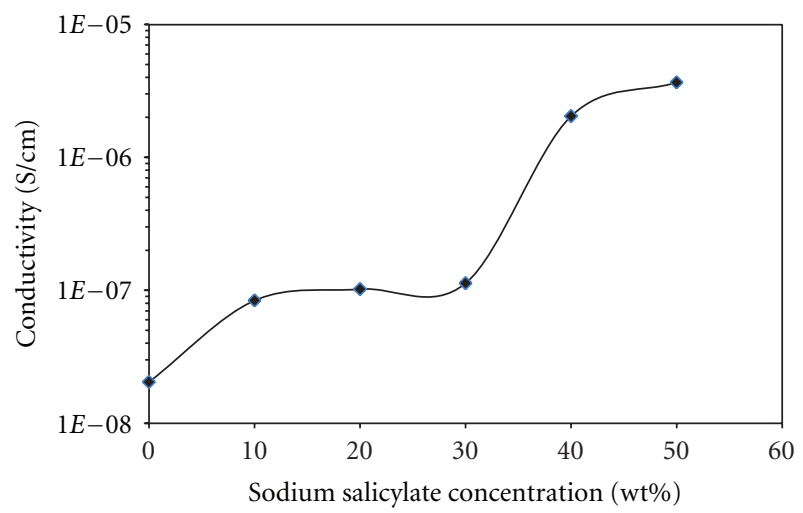

FIGURE 6: DC conductivity of PVA-sodium salicylate solid composite polymer electrolyte at ambient temperature for different SS concentrations.

carriers in polymer electrolyte system [2]. In Figure 4(b), it was found that the conductivity also increases with temperature up to $343 \mathrm{~K}$. When temperature increases, the free value mechanism increases the vibration of the molecules and this increases the space between them which causes the free ions to receive the thermal energy which increases the kinetic energy and thereby increasing the mobility of ions.

The ionic conductivity of the samples in this study was characterized using acimpedance spectroscopic technique. Figure 5(a) shows the Cole-cole plot for different concentrations of PVA-sodium salicylate polymer electrolyte at $303 \mathrm{~K}$. Typical plot consists of the high frequency semicircle and the low frequency spike. The high frequency semicircle

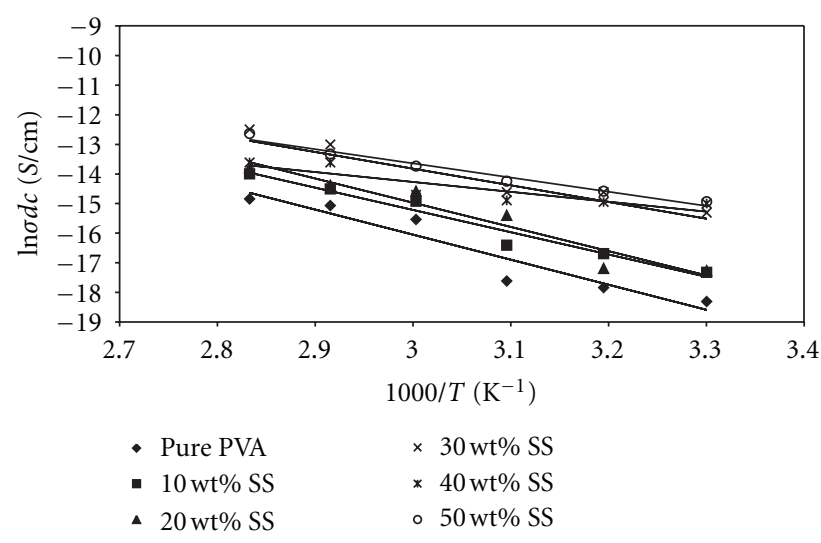

FIgure 7: The relationship between $\ln \sigma_{\mathrm{dc}}$ and $1000 / T$ of PVAsodium salicylate solid composite polymer electrolyte for different SS concentrations.

can be connected to the bulk conductivity of the polymer electrolytes [9] and the low frequency spike was due to the blocking electrode [7]. In Figure 5(a) it was found that with increase in concentration of sodium salicylate, the semicircle disappeared suggesting that only the resistive component prevailed [8]. However, the semicircle disappeared at high frequencies in the system at $50 \mathrm{wt} \%$ sodium salicylate as was shown in Figure 5(b). This is caused by the increase in the number of charge carriers due to dopant salt composition which reduces the bulk resistance and increase the electrical conductivity. 


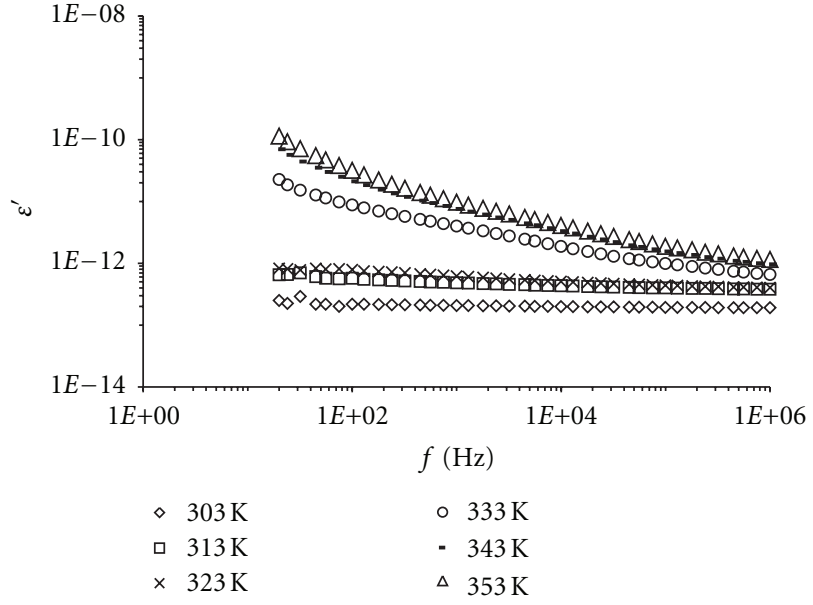

(a)

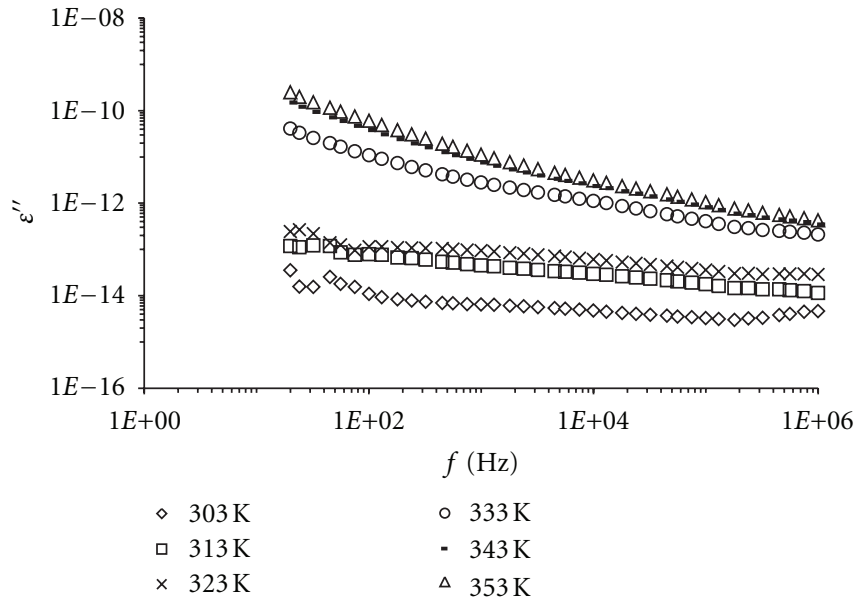

(b)

FIGURE 8: (a) Dielectric constant $\varepsilon^{\prime}$ of PVA: $50 \mathrm{wt} \%$ sodium salicylate solid composite polymer electrolyte at different temperatures. (b) Dielectric loss $\varepsilon^{\prime \prime}$ of PVA : $50 \mathrm{wt} \%$ sodium salicylate solid composite polymer electrolyte at different temperatures.

The dc conductivity $\sigma_{\mathrm{dc}}$ of the electrolytes was calculated by using (1) and the value of bulk resistance can be retrieved from the intercept of semicircle on the $Z^{\prime}$-axis of Cole-cole plot

$$
\sigma=\frac{l}{Z_{0} A}
$$

Figure 6 shows the dc conductivity for all composition of PVA-Sodium salicylate samples at ambient temperature. It was found that the conductivity increases with increasing temperature for all compositions as shown in Figure 7. The shape of the plot indicates that the relationship between $\ln \sigma$ and $1000 / T$ is almost linear therefore, the dc conductivity and temperature relationship obey Arrhenius law;

$$
\sigma_{\mathrm{dc}}=\sigma_{0} \exp \left(\frac{E_{A}}{k T}\right),
$$

where $\sigma_{0}$ is preexponential factor, $E_{A}$ is the conduction activation energy, $k$ is the Boltzmann constant, and $T$ is the temperature in Kelvin. The increase in conductivity with temperature in solid composite polymer electrolyte was due to the increase in the free volume of the system. The values of conduction activation energy at different temperatures were determined from the gradient of the Arrhenius plot $\ln \sigma_{\mathrm{dc}}$ versus $1000 / T$. The activation energy, which was a combination of defect formation and the energy of defect migration [2] influenced by temperature was the minimum energy required to overcome potential barrier of the system. The activation energy obtained were $0.729,0.687,0.706$, $0.486,0.288$, and $0.413 \mathrm{eV}$ for PVA, $10,20,30,40$, and $50 \mathrm{wt} \%$ SS, respectively. As sodium salicylate concentration increases, the value of conductivity increased and activation energy $E_{A}$ decreased.

3.5. Dielectric Properties. Figure 8(a) shows the variation of $\varepsilon^{\prime}$ with frequency for different temperatures from $303 \mathrm{~K}$ to
$353 \mathrm{~K}$ for pure PVA and PVA-sodium salicylate composite electrolytes. It can be seen that the $\varepsilon^{\prime}$ values decrease as frequency increases from $1 \mathrm{~Hz}$ to $1 \mathrm{MHz}$. This could be explained due to the dipoles which were not able to follow the variation field at higher frequencies [8]. The $\varepsilon^{\prime}$ increases towards low frequencies may be due to dielectric orientation polarization [16] and space charge polarization [7].

In Figure 8(a) it can be seen that $\varepsilon^{\prime}$ increases with the increase of temperature for PVA and PVA-sodium salicylate polymer electrolyte system. For polar and nonpolar material, the variation of $\varepsilon^{\prime}$ with temperature was different. In general, polar polymer has high $\varepsilon^{\prime}$, dependent on temperature. But in the case of nonpolar polymer, $\varepsilon^{\prime}$ is independent of temperature [8]. The $\varepsilon^{\prime}$ increases with increase in temperature of polar material due to facilitation in orientation of dipoles [17] and increasing mobility of charge carriers which tend to move freely as the temperature increase.

The same trend can be observed for the imaginary part of dielectric permittivity of the polymer system. Figure $8(\mathrm{~b})$ shows the variation of dielectric loss $\varepsilon^{\prime \prime}$ with frequency for all samples at different temperatures. The figure shows that the $\varepsilon^{\prime \prime}$ decreases as frequency increases. It can also be seen that as temperature increases, the value of $\varepsilon^{\prime \prime}$ increases. This is due to the contribution of mobility of free ions which increase with their kinetic energy and thermal energy.

Generally, the dielectric constant and dielectric loss shows a considerable increase when the temperature is increased may be due to polarization effect. The electron exchange interaction results in a local displacement of the electron in the direction of an electric field, which determines the polarization of the PVA-Sodium salicylate. The space charge polarization is governed by the numbers of space charge carriers with the rise in temperature the numbers of carriers increase resulting in an enhanced builtup space charge polarization and hence increase in dielectric properties. In other words, increasing the dielectric loss by increasing temperature is owing to the hopping of the charge 
carriers in the localized state and also due to the excitation of charge carriers to the states in the conduction band.

\section{Conclusion}

The solid composite polymer electrolyte of PVA-sodium salicylate was prepared by solution casting technique. The structure revealed the amorphous domains of the polymer which increased with increase of sodium salicylate concentration. The complexation and thermal stability were examined by FTIR and TGA, respectively. The conductivity and dielectric values were determined using ac impedance method. The conductivity increased with increase of sodium salicylate concentration and temperature. The dielectric constant and dielectric loss increased with the increase in temperature and decreased with the increase in sodium salicylate concentration. The PVA-50 wt\% sodium salicylate possesses highest conductivity, low activation energy, high amorphous nature and high thermal stability, and is suitable for application in electrochemical devices.

\section{References}

[1] J. Qiao, J. Fu, R. Lin, J. Ma, and J. Liu, "Alkaline solid polymer electrolyte membranes based on structurally modified PVA/PVP with improved alkali stability," Polymer, vol. 51, no. 21, pp. 4850-4859, 2010.

[2] M. Hema, S. Selvasekerapandian, G. Hirankumar, A. Sakunthala, D. Arunkumar, and H. Nithya, "Structural and thermal studies of PVA: $\mathrm{NH}_{4} \mathrm{I}$," Journal of Physics and Chemistry of Solids, vol. 70, no. 7, pp. 1098-1103, 2009.

[3] T. J. Benedict, S. Banumathi, A. Veluchamy, R. Gangadharan, A. Z. Ahamad, and S. Rajendran, "Characterization of plasticized solid polymer electrolyte by XRD and AC impedance methods," Journal of Power Sources, vol. 75, no. 1, pp. 171-174, 1998.

[4] S. Rajendran, M. Sivakumar, and R. Subadevi, "Li-ion conduction of plasticized PVA solid polymer electrolytes complexed with various lithium salts," Solid State Ionics, vol. 167, no. 3-4, pp. 335-339, 2004.

[5] G. K. Prajapati and P. N. Gupta, "Conduction mechanism in un-irradiated and $\gamma$-irradiated $\mathrm{PVA}^{-\mathrm{H}_{3}} \mathrm{PO}_{4}$ polymer electrolytes," Nuclear Instruments and Methods in Physics Research, Section B, vol. 267, no. 19, pp. 3328-3332, 2009.

[6] P. Nanda, S. K. De, S. Manna, U. De, and S. Tarafdar, "Effect of gamma irradiation on a polymer electrolyte: variation in crystallinity, viscosity and ion-conductivity with dose," Nuclear Instruments and Methods in Physics Research, Section B, vol. 268, no. 1, pp. 73-78, 2010.

[7] M. Hema, S. Selvasekerapandian, A. Sakunthala, D. Arunkumar, and H. Nithya, "Structural, vibrational and electrical characterization of PVA-NH4Br polymer electrolyte system," Physica B, vol. 403, no. 17, pp. 2740-2747, 2008.

[8] P. B. Bhargav, V. M. Mohan, A. K. Sharma, and V. V. R. N. Rao, "Investigations on electrical properties of (PVA:NaF) polymer electrolytes for electrochemical cell applications," Current Applied Physics, vol. 9, no. 1, pp. 165-171, 2009.

[9] J. Malathi, M. Kumaravadivel, G. M. Brahmanandhan, M. Hema, R. Baskaran, and S. Selvasekarapandian, "Structural, thermal and electrical properties of PVA- $\mathrm{LiCF}_{3} \mathrm{SO}_{3}$ polymer electrolyte," Journal of Non-Crystalline Solids, vol. 365, pp. 2277-2281, 2010.

[10] R. M. Hodge, G. H. Edward, and G. P. Simon, "Water absorption and states of water in semicrystalline poly(vinyl alcohol) films," Polymer, vol. 37, no. 8, pp. 1371-1376, 1996.

[11] M. C. Alvarez-Ros, S. Sánchez-Cortés, and J. V. García-Ramos, "Vibrational study of the salicylate interaction with metallic ions and surfaces," Spectrochimica Acta Part A, vol. 56, no. 12, pp. 2471-2477, 2000.

[12] E. M. Abdelrazek, I. S. Elashmawi, A. El-khodary, and A. Yassin, "Structural, optical, thermal and electrical studies on PVA/PVP blends filled with lithium bromide," Current Applied Physics, vol. 10, no. 2, pp. 607-613, 2010.

[13] C. C. Yang and Y. J. Lee, "Preparation of the acidic PVA/MMT nanocomposite polymer membrane for the direct methanol fuel cell (DMFC)," Thin Solid Films, vol. 517, no. 17, pp. 47354740, 2009.

[14] C. C. Yang, C. T. Lin, and S. J. Chiu, "Preparation of the PVA/HAP composite polymer membrane for alkaline DMFC application," Desalination, vol. 233, no. 1-3, pp. 137-146, 2008.

[15] S. Ramesh and A. K. Arof, "Ionic conductivity studies of plasticized poly(vinyl chloride) polymer electrolytes," Materials Science and Engineering B, vol. 85, no. 1, pp. 11-15, 2001.

[16] S. Ramesh, A. H. Yahaya, and A. K. Arof, "Dielectric behaviour of PVC-based polymer electrolytes," Solid State Ionics, vol. 152-153, pp. 291-294, 2002.

[17] A. Awadhia, S. K. Patel, and S. L. Agrawal, "Dielectric investigations in PVA based gel electrolytes," Progress in Crystal Growth and Characterization of Materials, vol. 52, no. 1-2, pp. 61-68, 2006. 

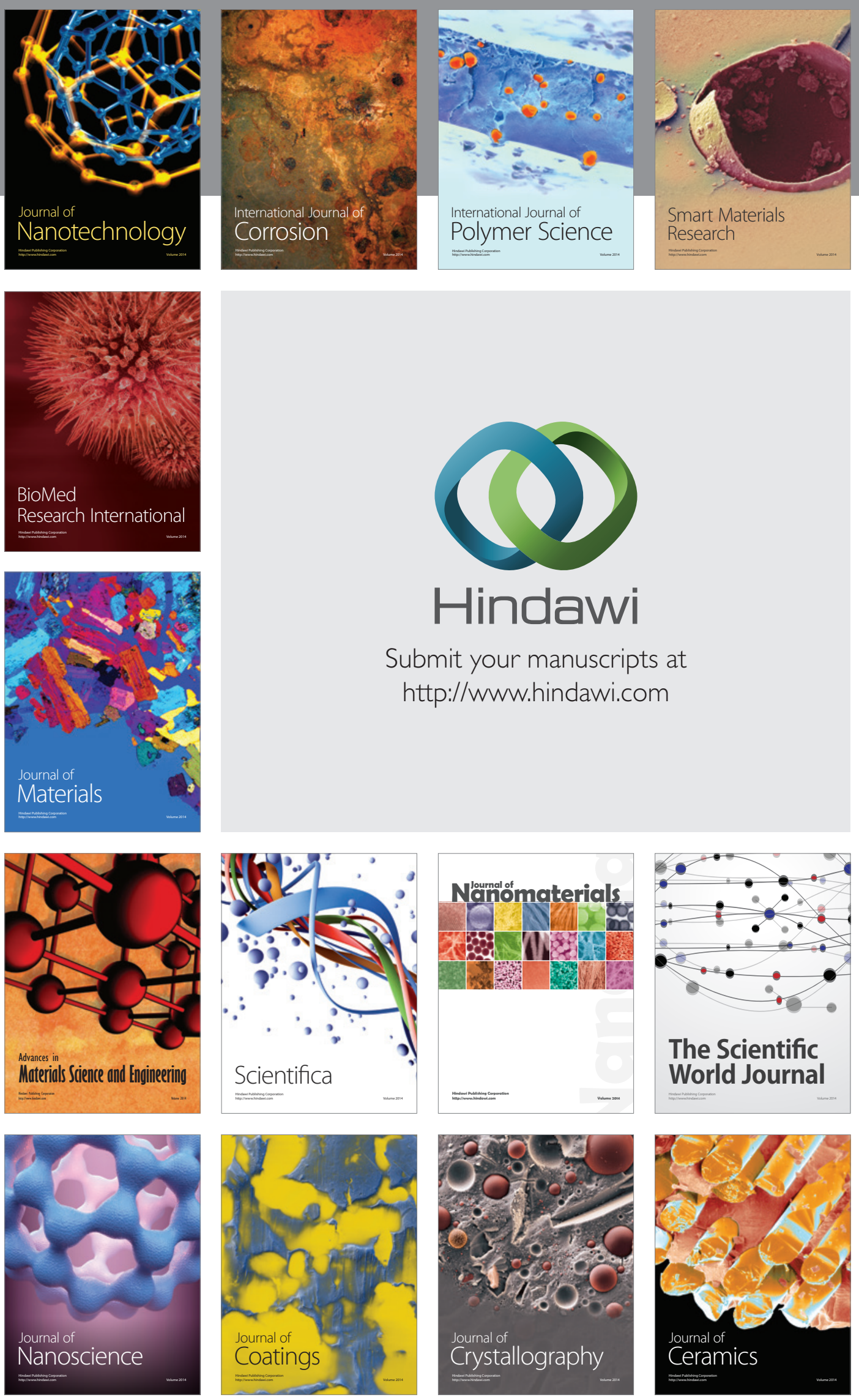

The Scientific World Journal

Submit your manuscripts at

http://www.hindawi.com

\section{World Journal}

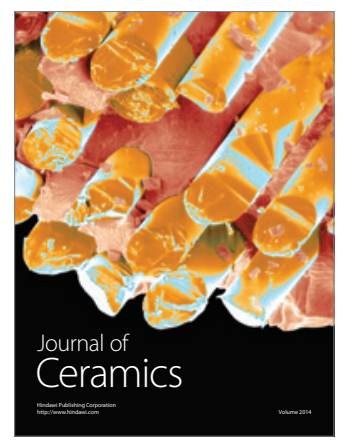

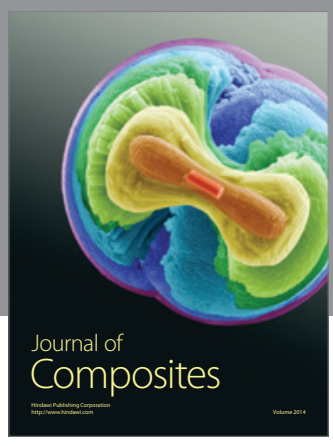
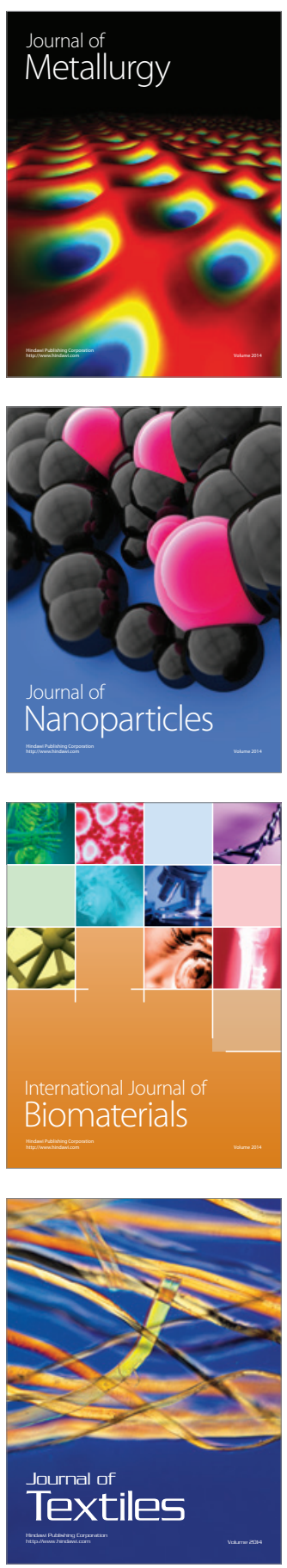